\title{
Оптические и электронные свойства пассивированных поверхностей $\operatorname{InP}(001)$
}

\author{
() П.А. Дементьев, Е.В. Дементьева, Т.В. Львова, В.Л. Берковиц, М.В. Лебедев
}

Физико-технический институт им. А.Ф. Иофрфе Российской академии наук, 194021 Санкт-Петербург, Россия

E-mail: demenp@yandex.ru

Поступила в Редакцию 9 апреля 2021 г.

В окончательной редакции 19 апреля 2021 г.

Принята к публикации 19 апреля 2021 г.

Исследовано влияние химической пассивации в растворах сульфида аммония $\left(\mathrm{NH}_{4}\right)_{2} \mathrm{~S}$ на оптические и электронные свойства поверхности $n$ - $\mathrm{InP}(001)$. Показано, что обработка в 4\%-м водном растворе $\left(\mathrm{NH}_{4}\right)_{2} \mathrm{~S}$ приводит к уменьшению приповерхностного поля и локализованных в этой области зарядов в 2 раза. Обработка в 4\%-м спиртовом растворе $\left(\mathrm{NH}_{4}\right)_{2} \mathrm{~S}$ приводит к уменьшению этих параметров в 3 раза, и, кроме того, в 3 раза уменьшается барьерная фотоэдс.

Ключевые слова: фосфид индия, спектроскопия анизотропного отражения, Кельвин-зонд микроскопия, локальная катодолюминесценция.

DOI: 10.21883/FTP.2021.08.51129.05

\section{1. Введение}

Наногетероструктуры на основе полупроводников $\mathrm{A}^{\mathrm{III}} \mathrm{B}^{\mathrm{V}}$ активно используются в современной электронике и оптоэлектронике. Одним из перспективных материалов для таких наногетероструктур является фосфид индия (InP), обладающий прямой запрещенной зоной шириной 1.34 эВ при комнатной температуре $[1,2]$, а также сравнительно низкой скоростью поверхностной безызлучательной рекомбинации [3].

Свойства поверхностей и интерфейсов в существенной степени определяют электронные и оптические характеристики наногетероструктур. Фосфид индия, как и другие полупроводники $\mathrm{A}^{\mathrm{III}} \mathrm{B}^{\mathrm{V}}$, является химически активным материалом, и даже кратковременный контакт с воздухом приводит к образованию на его поверхности многокомпонентного слоя естественных оксидов толщиной в несколько нанометров [4]. Формирование оксидного слоя сопровождается появлением поверхностных состояний, энергетически расположенных в запрещенной зоне InP. Одним из известных способов решения данной проблемы является пассивация поверхности полупроводникового кристалла сульфидными растворами. Как правило, для пассивации поверхности $\operatorname{InP}(100)$ используются водные растворы сульфида натрия $\left(\mathrm{Na}_{2} \mathrm{~S}\right)[5,6]$ или сульфида аммония $\left(\left(\mathrm{NH}_{4}\right)_{2} \mathrm{~S}\right)$ [7-10]. Эти растворы являются щелочными $(\mathrm{pH}>8)$. При обработке поверхности InP в таких растворах с нее удаляется оксидный слой, вместо которого формируется тонкое сульфидное покрытие, препятствующее повторному окислению поверхности и модифицирующее ее электронную структуру.

С другой стороны, спиртовые сульфидные растворы часто оказываются более эффективными, чем водные. Так, например, после обработки раствором $\left(\mathrm{NH}_{4}\right)_{2} \mathrm{~S}$ в изопропиловом спирте интенсивность фотолюминес- ценции нанопроволок $p$-InP возрастала намного сильнее, чем после обработки водным раствором сульфида аммония такой же концентрации [11]. Растворитель сульфидного раствора может оказывать существенное влияние на механизм фотоэлектрохимических реакций, модифицирующих атомную и электронную структуру поверхности полупроводника [12,13].

Цель данной работы - сравнение оптических и электронных свойств поверхностей $n-\operatorname{InP}(001)$, пассивированных растворами сульфида аммония в воде или в изопропиловом спирте. Для исследований использовалась оптическая методика спектроскопии анизотропного отражения (AO), а также оригинальные методики, основанные на сканирующей Кельвин-зонд микроскопии и локальной катодолюминесценции (КЛ).

\section{2. Образцы и методы исследования}

Для исследования использовались кристаллы $n$-InP $(001)$ с уровнем легирования $\sim 10^{18} \mathrm{~cm}^{-3}$. Перед пассивацией пластины InP кипятили в толуоле, a затем в ацетоне с последующей промывкой в воде для очистки от органических загрязнений. Для исследования роли растворителя в процессе пассивации поверхности $n$-InP(001) использовали водный и спиртовой растворы сульфида аммония. Для приготовления растворов использовался стандартный раствор сульфида аммония $\left(\left(\mathrm{NH}_{4}\right)_{2} \mathrm{~S} \quad\left(40-48 \%\right.\right.$ по масcе в $\left.\mathrm{H}_{2} \mathrm{O}\right)$, Merck-SigmaAldrich). В одном случае он разбавлялся водой, а в другом - изопропиловым спиртом (2-РА) в соотношении 1:9 так, чтобы объемная концентрация сульфидов в растворах составляла $\sim 4 \%$. Образцы обрабатывались в растворах в течение 10 мин при комнатной температуре. После сульфидной обработки образцы промывали водой или изопропиловым спиртом, 
в соответствии с рассматриваемым сульфидным раствором, а затем высушивали на воздухе. Используемый в качестве эталонного исходный необработанный образец подвергался только предварительной очистке.

Для контроля изменения величины приповерхностного электрического поля использовалась бесконтактная оптическая методика спектроскопии анизотропного отражения (AО). В данной методике измеряется спектр сигнала анизотропии, который описывается следующим выражением:

$$
\frac{\Delta R}{R}=2 \frac{R_{\alpha}-R_{\beta}}{R_{\alpha}+R_{\beta}} .
$$

Для поверхности (001) $R_{\alpha}$ и $R_{\beta}-$ коэффициенты отражения света, линейно поляризованного вдоль осей поверхности [1ㅣㅁ и [110] соответственно. Установка для регистрации спектров АО подробно описана в работе [14], поэтому отметим лишь ее основные особенности. Использование ксеноновой лампы в качестве источника возбуждения и фотоумножителя с чувствительностью вплоть до ультрафиолетового диапазона в качестве детектора отраженного света позволяет измерять спектры в диапазоне энергий фотонов от 2 до 5.5 эВ. Линейная поляризация света, нормально падающего на поверхность, модулировалась кварцевым фотоупругим модулятором с частотой 100 кГц между направлениями осей [110] и [1ํㅣㄹ в плоскости (001) кристаллов. Полученный модулированный сигнал с фотоумножителя анализировался стандартным синхронным детектором. При этом питание фотоумножителя изменялось системой обратной связи таким образом, чтобы среднее значение фототока сохранялось во всем спектральном диапазоне. В результате выходной сигнал синхронного детектора оказывается пропорциональным величине сигнала анизотропии $\Delta R / R$.

Для анализа изменений электрофизических свойств поверхности InP после пассивации было проведено исследование влияния внешнего освещения на локальный потенциал поверхности. Для этого использовалась стандартная методика сканирующей Кельвин-зонд микроскопии, реализованная на зондовой станции NTegra Aura (NT-MDT, г. Москва, Россия) с использованием коммерческих зондов HA_FM/W ${ }_{2} \mathrm{C}$ (NT-MDT). Для устранения засветки от лазера детектирующей системы атомносилового микроскопа применялась сканирующая головка, оборудованная инфракрасным лазером (длина волны $>1.1$ мкм). Внешняя подсветка создавалась белой светодиодной лампой. Исследование изменений потенциала осуществлялось на малой площади $(\sim 100 \times 100$ нм $)$, для того чтобы минимизировать влияние возможных неоднородностей в распределении потенциала на поверхности. Начало регистрации потенциала происходило в темноте, затем включалось внешнее освещение, которое оставалось включенным до стабилизации уровня потенциала. После этого освещение выключалось и оставалось выключенным так же до стабилизации потенциала поверхности. Для набора статистики такой цикл повторялся в процессе сканирования 2-3 раза. При этом скорость сканирования в течение всего кадра сохранялась постоянной, что позволило нам перенормировать ось медленного сканирования из единиц длины (нм) в единицы времени (c).

Исследования катодолюминесцентных свойств пленок и динамики поглощенного тока электронного пучка проводились на электронно-зондовом микроанализатоpe CAMEBAX (Cameca, Франция), оснащенном оптическим спектрометром оригинальной конструкции для регистрации спектров катодолюминесценции [15]. Измерения спектров катодолюминесценции, динамики интенсивности КЛ и поглощенного тока проводили при энергиях электронного пучка 2.5 и 10 кэВ, токе электронного пучка 5 нА и диаметре 30 мкм при комнатной температуре. Измерение спектров при различных энергиях первичных электронов позволяет исследовать изменение люминесцентных свойств по глубине. С помощью программы CASINO [16] были рассчитаны распределения потерянной электронами энергии по глубине в объемном образце InP для различных энергий первичных электронов. Показано, что при энергии 2.5 кэВ электроны теряют энергию в основном в верхних $30 \mathrm{Hм}$, а при энергии 10 кэВ - в области толщиной > 500 нм. Методика измерения поглощенного тока описана в статье [17].

\section{3. Результаты}

Измеренные спектры АО исследованных образцов n-InP представлены на рис. 1.

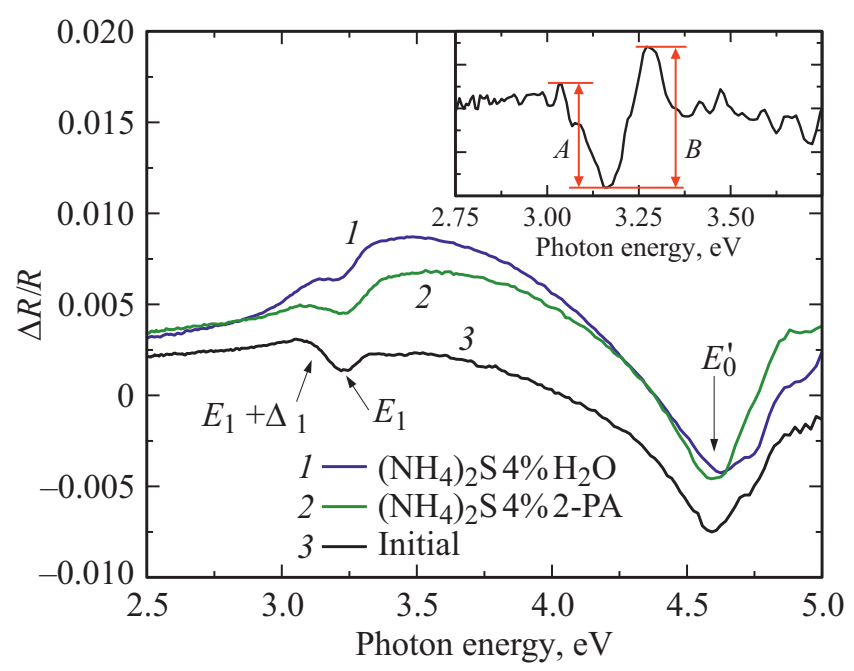

Рис. 1. Спектры анизотропного отражения исследованных образцов в диапазоне 2.5-5.0 эВ. 1,2 - образцы, обработанные в водном и спиртовом растворах $\left(\mathrm{NH}_{4}\right)_{2} \mathrm{~S}$ соответственно; 3 - исходный образец. Стрелками показано положение переходов $E_{0}^{\prime}, E_{1}$ и $E_{1}+\Delta_{1}$. На вставке - вид производной спектра АО в области переходов $E_{1}$ и $E_{1}+\Delta_{1}$; показаны амплитуды осцилляции $\mathrm{A}, \mathrm{B}$, по которым производился расчет приповерхностного электрического поля. 
Спектры имеют вид, характерный для кристаллов $n$-InP [18]. В них содержатся особенности, связанные с известными объемными переходами $E_{0}^{\prime}$ в области 4.7 эВ, и переходами $E_{1}$ и $E_{1}+\Delta_{1}$ в области $3.0-3.2$ эВ. Появление сигналов анизотропии в кубическом кристалле связывается с приповерхностным электрическим полем области объемного заряда, которое вызывает анизотропию электрооптического эффекта, наблюдаемую в области объемных переходов. Величина такой анизотропии для поверхности (001) пропорциональна напряженности поля $E_{s}$ на поверхности кристалла, которая описывается выражением

$$
E_{s}=\sqrt{\frac{2 e V N_{d}}{\varepsilon \varepsilon_{0}}}
$$

В формуле (2) $E_{s}-$ напряженность электрического поля у поверхности, $\mathrm{eV}$ - величина приповерхностного поля, $N_{d}-$ концентрация активной примеси, $\varepsilon-$ статическая диэлектрическая проницаемость кристалла, $\varepsilon_{0}-$ электрическая постоянная.

В нашей работе контроль величины приповерхностного поля осуществлялся по амплитуде сигналов анизотропии в области объемных переходов $E_{1}$ и $E_{1}+\Delta_{1}$. Однако, как видно из рис. 1 , в этой области также присутствует широкий бесструктурный и интенсивный сигнал, не связанный с приповерхностным полем, а определяемый толщиной и диэлектрической проницаемостью покрытия поверхности [19]. Присутствие такого сигнала затрудняет контроль изменения амплитуды сигнала спектров. Поэтому для анализа спектров была использована процедура, предложенная в [20]. От измеренных спектров рассчитывалась производная по длине волны (энергии фотона). Пример получаемого результата для исходного образца приведен на вставке к рис. 1. Затем аналогично [20] измерялась амплитуда полученной осцилляции как полусумма осцилляций $\mathrm{A}$ и В, показанных стрелками на вставке к рис. 1. Эта амплитуда зависит линейно от напряженности поля $E_{s}$, определяемой выражением (2), и корневым образом от величины приповерхностного поля. Таким образом, квадрат отношения амплитуды сигналов анизотропии в обработанных образцах относительно исходного (окисленная поверхность) позволяет оценить относительное изменение электрического поля у поверхности образцов. Нами было получено, что обработка в водном растворе $\left(\mathrm{NH}_{4}\right)_{2} \mathrm{~S}$ приводит к уменьшению поля более чем в 2 раза, а в спиртовом растворе - почти в 3 раза.

Методом Кельвин-зонд микроскопии были изучены изменения поверхностного потенциала образцов. Было обнаружено, что при включении и выключении внешнего освещения на поверхности происходит несколько процессов, приводящих к изменению поверхностного потенциала (рис. 2). На рис. 2 приведено поведение потенциала в случае образца, обработанного в водном растворе $\left(\mathrm{NH}_{4}\right)_{2} \mathrm{~S}$, так как именно на этом образце наиболее ярко видны эффекты, о которых пойдет речь далее.

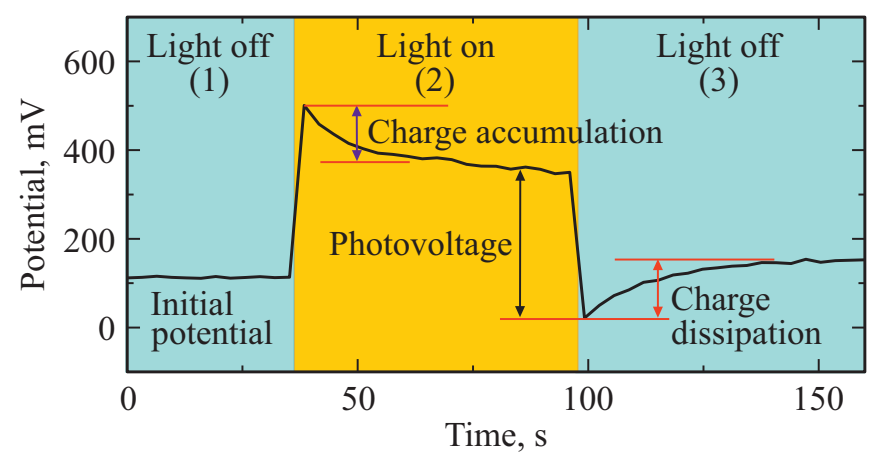

Рис. 2. Типичное изменение потенциала поверхности после включения внешнего освещения (область 2) и после его выключения (область 3). Стрелками показаны изменения, связанные с барьерной фотоэдс (большая стрелка), а также накоплением и диссипацией зарядов.

Непосредственно в момент включения внешнего освещения наблюдается резкое изменение потенциала поверхности, связанное с возникновением на поверхности так называемой барьерной фотоэдс. Как известно, величина фотоэдс связана с величиной электрического поля в области пространственного заряда (ОПЗ). Таким образом, по изменению фотоэдс после обработки кристаллов растворами сульфида аммония можно судить об изменении электрического поля на поверхности. Как видно из рис. 2, при включении внешнего освещения потенциал поверхности возрастает, свидетельствуя о том, что в данном случае неосновными носителями являются дырки, так как именно они локализуются на поверхности под действием поля ОПЗ. После выключения внешнего освещения происходит обратный процесс. Именно величина изменения потенциала при выключении света и была взята нами в качестве величины фотоэдс в силу особенностей схемы включения освещения, которые могли вносить неконтролируемую ошибку в первоначальный скачок потенциала. Измеренные значения барьерной фотоэдс представлены в таблице. Как видно, обработка в спиртовом растворе $\left(\mathrm{NH}_{4}\right)_{2} \mathrm{~S}$ приводит к значительному (в 3 раза) снижению величины барьерной фотоэдс. С другой стороны, в случае обработки в водном растворе $\left(\mathrm{NH}_{4}\right)_{2} \mathrm{~S}$ изменения барьерной фотоэдс практически не наблюдается.

Зависимость измеряемых параметров от способа обработки кристаллов

\begin{tabular}{l|c|c|c}
\hline \multicolumn{1}{c|}{ Обработка } & $\begin{array}{c}\text { Барьерная } \\
\text { фотоэдс, } \\
\text { мВ }\end{array}$ & $\begin{array}{c}\text { Амплитуда } \\
\text { диссипации } \\
\text { зарядов, мВ }\end{array}$ & $\begin{array}{c}\text { Время } \\
\text { диссипации } \\
\text { зарядов, с }\end{array}$ \\
\hline Без обработки & 280 & 20 & 10 \\
$\begin{array}{l}\text { В водном } \\
\text { растворе }\left(\mathrm{NH}_{4}\right)_{2} \mathrm{~S}\end{array}$ & 310 & 130 & 18 \\
$\begin{array}{l}\text { В спиртовом } \\
\text { растворе }\left(\mathrm{NH}_{4}\right)_{2} \mathrm{~S}\end{array}$ & 115 & 70 & 17
\end{tabular}


Кроме барьерной фотоэдс в картине изменения потенциала наблюдаются медленные процессы после включения и выключения света. Как видно из рис. 2, наблюдается постепенное уменьшение потенциала в процессе длительного воздействия света и, напротив, его увеличение в темноте. Процесс связан с накоплением зарядов, в данном случае электронов, на поверхностных состояниях и в диэлектрических слоях на поверхности образцов под действием света и их диссипацией после выключения света. Как и в случае барьерной фотоэдс, количественно оценивались процессы диссипации как наименее искаженные процессами включения света. Нами были проанализированы амплитуда этих изменений, а также их характерное время. Полученные данные приведены в таблице. Видно, что обработка в растворах сульфида аммония приводит к значительному увеличению количества аккумулируемых на поверхности зарядов. Мы считаем, что это связано с наличием на поверхности диэлектрических слоев сульфидов/оксидов индия [5].

На рис. 3 приведены спектры КЛ, измеренные при энергии первичных электронов 2.5 кэВ. Кроме того, были получены спектры КЛ при 10 кэВ, которые не отличаются по структуре и форме от спектров, полученных при 2.5 кэВ. Во всех спектрах КЛ, полученных на исследуемых образцах, наблюдается полоса с максимумом при 1.34 эВ. Данная полоса связана с краевой люминесценцией InP. Положение полосы постоянно для всех образцов, однако для образца, обработанного в спиртовом растворе $\left(\mathrm{NH}_{4}\right)_{2} \mathrm{~S}$, наблюдается существен-

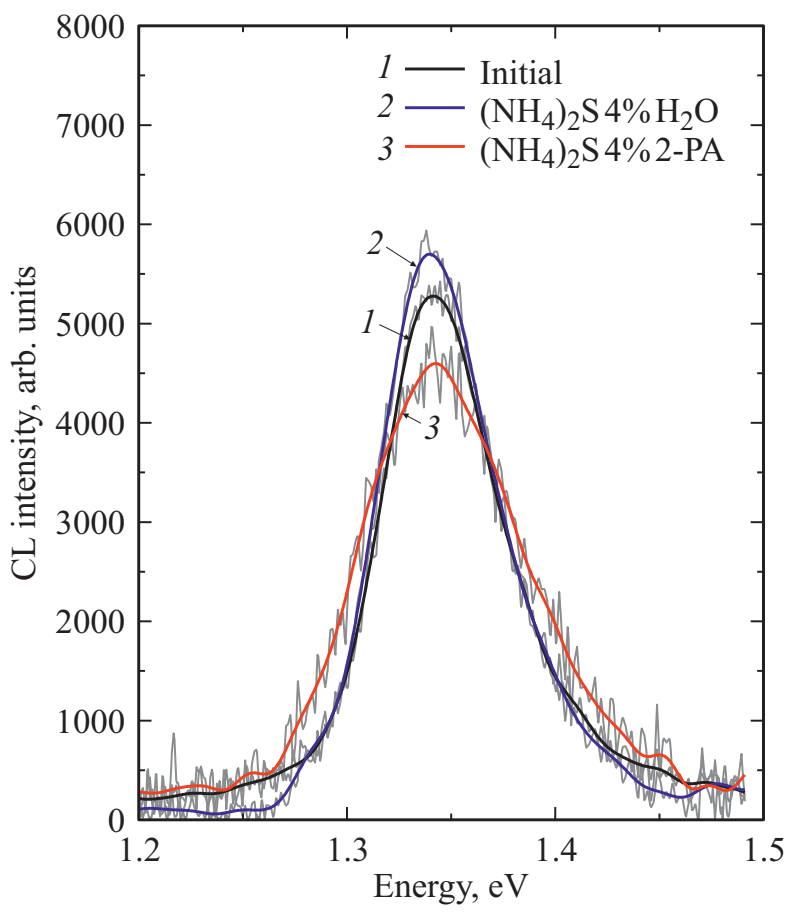

Pис. 3. Спектры катодолюминесценции (CL) образцов: 1 - исходный, 2 - обработанный в водном растворе $\left(\mathrm{NH}_{4}\right)_{2} \mathrm{~S}$, 3 - обработанный в спиртовом растворе $\left(\mathrm{NH}_{4}\right)_{2} \mathrm{~S}$. Измерения при энергии первичных электронов 2.5 кэВ.
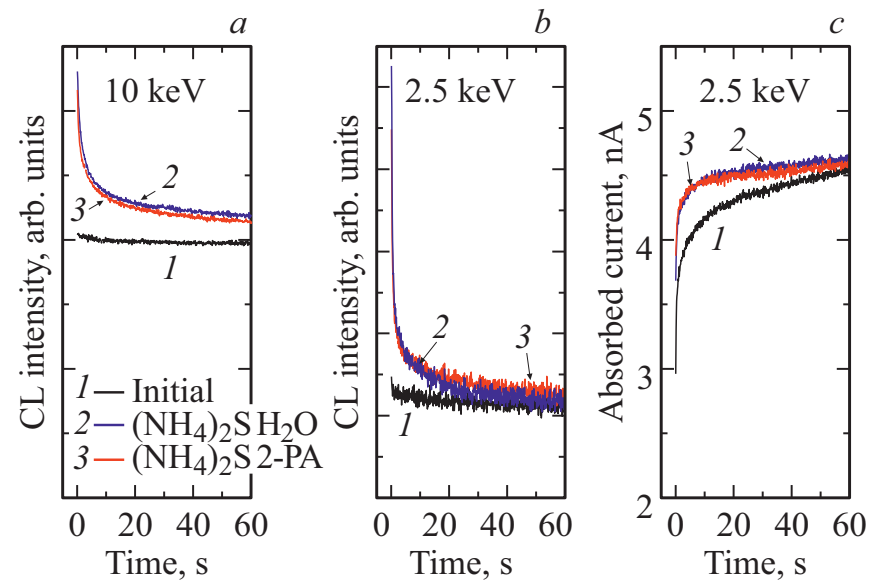

Рис. 4. Зависимости интенсивности полосы катодолюминесценции $(\mathrm{CL})$ с максимумом при 1.34 эВ $(a, b)$ и поглощенного тока $(c)$ от времени облучения электронным пучком исходного (1), обработанного в водном растворе $\left(\mathrm{NH}_{4}\right)_{2} \mathrm{~S}$ (2) и обработанного в спиртовом растворе $\left(\mathrm{NH}_{4}\right)_{2} \mathrm{~S}$ (3) образцов, измеренные при энергии первичных электронов 10 кэВ $(a)$ и 2.5 кэВ $(b, c)$.

ное увеличение полуширины и при 2.5 кэВ, и при 10 кэВ. Соответственно, данные изменения не связаны со способом обработки поверхности, а связаны с объемными свойствами этого образца.

Были измерены зависимости интенсивности полосы КЛ с максимумом 1.34 эВ и поглощенного тока от времени при постоянном облучении электронным пучком (рис. 4). Видно, что интенсивность полосы 1.34 эВ в исходном образце практически не меняется при облучении пучком, а в образцах, подвергнутых обработке, в начальный момент времени наблюдается существенно бо́льшая интенсивность полосы 1.34 эВ. При этом наблюдается затухание интенсивности с характерным временем $\sim 10$ с. Был оценен вклад затухающей составляющей в начальную интенсивность полосы 1.34 эВ. При энергии электронного пучка 2.5 кэВ этот вклад составляет $80 \%$, а при энергии электронов 10 кэВ $-32 \%$. Соответственно, увеличение интенсивности после пассивации связано с поверхностным слоем, а наблюдаемое затухание интенсивности - с влиянием электронного пучка на пассивированную поверхность.

Были проведены измерения изменения поглощенного тока при длительном облучении электронным пучком. По изменению поглощенного тока видно, что при облучении электронным пучком в образцах наблюдается локализация электронов $[17,21]$. Из этих данных была проведена оценка заряда, накапливаемого в облучаемой области. В исходном образце эта величина составляет 9.7 нКл. После обработки в растворах сульфида аммония количество накапливаемых зарядов заметно уменьшается - до 3.7 нКл при обработке в водном растворе и 2.5 нКл при обработке в спиртовом растворе $\left(\mathrm{NH}_{4}\right)_{2} \mathrm{~S}$. Как можно заметить, данные изменения хорошо согласу- 
ются с рассчитанным уменьшением приповерхностного поля и в случае спиртового раствора с уменьшением величины барьерной фотоэдс.

Следует отметить, что после пассивации электронные и оптические свойства поверхности сохраняются по крайней мере в течение нескольких месяцев.

\section{4. Заключение}

В настоящей работе проведен сравнительный анализ оптических и электронных свойств $n-\operatorname{InP}(001)$, обработанных водным и спиртовым раствором сульфида аммония и показано существенное влияние растворителя. С помощью спектроскопии анизотропного отражения, сканирующей Кельвин-зонд микроскопии и локальной катодолюминесценции показано, что пассивация приводит к значительному изменению параметров, связанных с поверхностными состояниями и диэлектрическими слоями на поверхности. Так, в случае обработки в водном растворе приповерхностное поле уменьшается в 2 раза, а в случае спиртового сульфидного раствора в 3 раза. Аналогичные изменения наблюдаются и в оцененном нами заряде, локализованном на электронных поверхностных ловушках.

Из зависимости потенциала поверхности от времени освещения следует, что пассивация в спиртовом раствоpe $\left(\mathrm{NH}_{4}\right)_{2} \mathrm{~S}$ почти в 3 раза снижает величину барьерной фотоэдс. С другой стороны, отсутствие изменения барьерной фотоэдс в случае пассивации в водном растворе не согласуется с остальными данными, полученными в настоящей работе, и требует дополнительного изучения.

\section{Финансирование работы}

Работа частично поддержана Российским фондом фундаментальных исследований (РФФИ) (проект № 20-0300523).

\section{Конфликт интересов}

Авторы заявляют, что у них нет конфликта интересов.

\section{Список литературы}

[1] P. Lautenschlager, M. Garriga, M. Cardona. Phys. Rev. B, 36, 4813 (1987).

[2] L. Pavesi, F. Piazza, A. Rudra, J.F. Carlin, M. Ilegems. Phys. Rev. B, 44, 9052 (1991).

[3] H.J. Joyce, J. Wong-Leung, C.-K. Yong, C.J. Docherty, S. Paiman, Q. Gao, H.H. Tan, C. Jagadish, J. Lloyd-Hughes, L.M. Herz, M.B. Johnston. Nano Lett., 12, 5325 (2012).

[4] G. Hollinger, E. Bergignat, J. Joseph, Y. Robach. J. Vac. Sci. Technol. A, 3, 2082 (1985).

[5] M.V. Lebedev, Yu.M. Serov, T.V. Lvova, R. Endo, T. Masuda, I.V. Sedova. Appl. Surf. Sci., 533, 147484 (2020).

[6] M.V. Lebedev, Yu.M. Serov, T.V. Lvova, I.V. Sedova, R. Endo, T. Masuda. Semiconductors, 54, 1843 (2020).
[7] C.E.J. Mitchell, I.G. Hill, A.B. McLean, Z.H. Lu. Progr. Surf. Sci., 50, 325 (1995).

[8] S. Tian, Z. Wei, Y. Li, H. Zhao, X. Fang, J. Tang, D. Fang, L. Sun, G. Liu, B. Yao, X. Ma. Mater. Sci. Semicond. Process., 17, 33 (2014).

[9] C.-F. Yen, M.-K. Lee. J. Vac. Sci. Technol. B, 30, 052201 (2012).

[10] H.-K. Kang, Y.-S. Kang, M. Baik, K.-S. Jeong, D.-K. Kim, J.-D. Song, M.-H. Cho. J. Phys. Chem. C, 122, 7226 (2018).

[11] N. Tajik, C.M. Haapamaki, R.R. LaPierre. Nanotechnology, 23, 315703 (2012).

[12] T.V. Lvova, A.L. Shakhmin, I.V. Sedova, M.V. Lebedev. Appl. Surf. Sci., 311, 300 (2014).

[13] М.В. Лебедев, Т.В. Львова, А.Л. Шахмин, О.В. Рахимова, П.А. Дементьев, И.В. Седова. ФТП, 53, 908 (2019).

[14] V.L. Berkovits, V.N. Bessolov, T.V. L'vova, V.I. Safarov, R.V. Khasieva, B.V. Tsarenkov. J. Appl. Phys., 70, 3707 (1991).

[15] M.V. Zamoryanskaya, S.G. Konnikov, A.N. Zamoryanskii. Instrum. Exp. Techn., 47 (4), 477 (2004).

[16] P. Hovington, D. Drouin, R. Gauvin. Scanning, 19, 1 (1997).

[17] П.А. Дементьев, Е.В. Иванова, М.В. Заморянская. ФТТ, 61 (8), 1448 (2019).

[18] N. Esser, W.G. Schmidt, J. Bernholc, A.M. Frisch, P. Vogt, M. Zorn, M. Pristovsek, W. Richter, F. Bechstedt, Th. Hannappel, S. Visbeck. J. Vac. Sci. Technol. B, 17, 1691 (1999).

[19] V.L. Berkovits, V.A. Kosobukin, A.B. Gordeeva. J. Appl. Phys., 118, 245305 (2015).

[20] T. Holden, W.D. Sun, F.H. Pollak, J.L. Freeouf, D. McInturff, J.M. Woodall. Phys. Rev. B, 58, 7795 (1998).

[21] E.V. Ivanova, P.A. Dementev, T.V. Lvova, M.V. Lebedev. J. Phys.: Conf. Ser., 1697 (1), 012061 (2020).

Редактор Л.В. Шаронова

\section{Optical and electronic properties of passivated InP (001) surfaces}

\author{
P.A. Dementev, E.V. Dementeva, T.V. Lvova, \\ V.L. Berkovits, M.V. Lebedev \\ loffe Institute, \\ 194021 St.Petersburg, Russia
}

Abstract The effect of chemical passivation in solutions of ammonium sulfide $\left(\mathrm{NH}_{4}\right)_{2} \mathrm{~S}$ on the optical and electronic properties of an $n$-InP(001) surface has been studied. It has been shown that treatment in a $4 \%$ aqueous solution of $\left(\mathrm{NH}_{4}\right)_{2} \mathrm{~S}$ leads to a decrease of surface band bending and localized charges in nearsurface region in the 2 times. Processing in a $4 \%$ alcoholic solution of $\left(\mathrm{NH}_{4}\right)_{2} \mathrm{~S}$ leads to a decrease in these parameters in 3 times, and moreover, the barrier photovoltage also reduces in 3 times. 